\title{
Dealing with the Unthinkable: a Study of the Cognitive and Emotional Stress of Adult and Child Homicide Investigations on Police Investigators
}

\author{
Jason Roach $^{1}$ (D) Ashley Cartwright ${ }^{2} \cdot$ Kathryn Sharratt $^{1}$ \\ Published online: 5 November 2016 \\ (C) The Author(s) 2016. This article is published with open access at Springerlink.com
}

\begin{abstract}
Although the death of a child is without doubt one of the most distressing events imaginable, when it occurs in suspicious circumstances, such as at the hand of a parent or close family member, its effects are often more acute and incomprehensible. This paper presents an exploratory study comparing the cognitive and emotional stressors experienced by police when investigating child and adult homicides. The results of an online survey questionnaire with 99 experienced UK police investigators are presented, with key differences found in the cognitive and emotional stress experienced depending on whether the victim is a child or an adult, key differences and similarities identified in the ways investigators deal and cope with adult and child homicide cases, with a tentative discussion of the implications for the well-being and training of police investigators provided.
\end{abstract}

Keywords Police stress · Homicide investigation · Coping strategies $\cdot$ Cognitive and emotional effects

\section{Introduction}

A popular fictional characterisation of detectives is one which portrays them as possessing a gift for solving the most mysterious of murders but at the expense of being otherwise totally flawed human beings unable to connect with others on an

Jason Roach

j.roach@hud.ac.uk

1 Applied Criminology Centre, University of Huddersfield, Queensgate, Huddersfield HD1 3DH, UK

2 Leeds Trinity University, Leeds, UK emotional level. The portrayal of detectives in this way leads one to conclude that this is either because the work they do is so emotionally charged and gruesome that they cannot cope with emotional connections to others or that the job itself attracts a certain kind of person or personality, impervious to the emotional and cognitive stressors and pressures generated by a murder enquiry. Either way, it probably accounts for why we tend to consider them a different breed to the rest of us and hence our fascination with them.

In reality, evidence suggests the contrary to be true. Police officers do not seem impervious to the stresses, strains and pressures associated with their job, particularly those who investigate violent crimes such as homicide (Anshel 2000; Kohan and O'Connor 2002; Violanti 2005). Few would argue that police officers are not exposed to many acute and chronic life stressors than those in other professions and are more at risk developing symptoms of poor mental health including anxiety, depression and post-traumatic stress disorder (PTSD) as a consequence. As a final nod to the common misrepresentation of detectives in crime fiction alluded to earlier, Huey and Broll (2015) found in a recent study with police investigators that although the public may find police work glamorous and exciting, criminal investigators do not.

The present paper details the findings of a small exploratory study that focuses not just on common cognitive stressors (e.g. intrusive thoughts, preoccupation with a case and the influence of bias) and the effects of emotional stressors (e.g. disrupted sleep patterns, low mood and intense emotional pressure to resolve a case for the family of a victim) commonly generated by homicide investigations, but, for a first time, whether identifiable differences exist in the form and intensity of these effects depending on whether the homicide being investigated has a child (or children) as opposed to an adult (or adults) victim. Additionally, common ways that investigators deal or cope with homicide investigations are identified 
with again comparison made between adult and child homicide investigations. We begin with a brief discussion of the research literature pertaining to 'police stress'.

\section{Policing: a Stressful Occupation}

\section{Lazarus and Folkman define stress as}

'a particular relationship between the person and the environment that is appraised by the person as taxing or exceeding his or her resources and endangering his or her well-being' (1984, p.19).

A number of studies have shown a higher prevalence of stress-related problems among police officers than with members of the general public, including heart disease, cancer, alcohol dependency, drug abuse and divorce (e.g. Anshel 2000; Kohan and O'Connor 2002; and Violanti 2005). Four classifications of different stressors have been identified as significant causes of stress for police officers: (1) those extrinsic to the organisation, (2) occupational (i.e. task/job related), (3) personal and (4) organisational (e.g. Hart et al. 1993; Finn and Tomz 1996; Abdollahi 2002; Oliver and Meir 2004). Although a detailed discussion of each is beyond the remit of the present paper (but are explored in a sister paper currently in production), it suffices to say that all, to different degrees, are likely to be experienced by police homicide investigators. Salo and Allwood suggest that although officers on patrol duty have stressful events imposed on them from the outside and in real time (e.g. breaking up a pub fight), stress experienced by criminal investigators 'may still be very real', for example, when meeting the families of murder victims (2011, p98). In an unpublished study, Holmberg, Christianson and Karlsson (2004 cited by Salo and Allwood 2011) asked 400 Swedish police officers to report the most psychologically stressful event of their careers (to date) and found no statistically significant difference in the psychological stress reported when these events were divided into the categories 'experienced on patrol' and 'experienced on investigative duty'. It is not clear, however, how many of the 'investigative events' included the suspicious death of a child, but it is unlikely statistically that many of the investigator respondents had experienced investigating such an event. Conversely, it is not clear how many of the experienced on patrol events reported involved the death of a child, for example in road traffic accident or indeed whether the patrol officers were first to the scene of a suspicious child death. Without such clarity, any conclusions drawn from this study must be tentative.

Lazarus (1966) pinpoints three opportunities for the recognition and cognitive processing of stress perceptions: primary appraisal, secondary appraisal and reappraisal. Primary appraisal refers to the perceptual and cognitive processes by which an individual recognises a stressor as stressful. Secondary appraisal involves the selection of a response to a stressor, with reappraisal being assessing the stressfulness of a situation anew. Although some of the cognitive and emotional stressors likely to be experienced by criminal investigators (including homicide) will be similar to other policing colleagues (albeit perhaps to different degrees), it's equally likely that they will experience different stressors generated by the investigation of homicide. We now turn briefly to the literature on investigative decision-making before moving to how $\operatorname{cog}$ nitive and emotional stressors generated by homicide investigations are identified and how they might be minimised and dealt with by investigators. Put simply, how do homicide investigators cope in such emotive and stressful investigative contexts?

\section{Homicide, Investigative Decision-Making and Stress}

If police investigators are not robots, then the investigation of homicide is likely to induce stresses that can adversely affect their decision-making. Investigative decision-making research to date has tended to focus on different types of cognitive bias which can impede, or even derail, a criminal investigation (e.g. Stelfox and Pease 2005; Ask and Granhag 2007; Rossmo 2009; Roach and Pease 2009). The timing and mode of critical decision-making has also been researched with, for example, investigator 'intuition' (Wright 2013) and identification of common 'tipping points' in a decision to charge a suspect in homicide investigations (Fahsing and Ask 2013). If, how, and when investigative decision-making is affected by the cognitive and emotional stressors associated with investigating adult or child homicides and how this might trigger (or interact with) cognitive and emotional bias remains unknown and is a focus of the present paper.

With regard to improving investigator decision-making and making it more consistent (well at least less idiosyncratic) in England and Wales, procedural guidance has been available to police investigators for more than a decade, exemplified by the Murder Investigation Manual (2006). This is mainly due to the recognition that criminal investigation, particularly homicide, necessitates both additional knowledge and an additional skill set (e.g. Smith and Flanagan 2000; Nicol et al. 2004). To improve police investigative competency investigative guidance, such as the Practice Advice for Core Investigative Doctrine (2005a), the Murder Investigation Manual ( 2006) and Guidance on the Major Incident Room Standard Administrative Procedures (2005b) provide procedural and practice guidance for criminal investigators to follow and a baseline with which reviewing officers can measure individual investigative performance.

The utility of these guides for police investigators is not disputed here. After all, by providing investigators with an established set of processes and procedures to follow, 
procedural stress experienced by investigators is likely to be reduced. To our knowledge, however, none of these provide guidance and help on how investigators can identify and deal with the stressors likely to be generated by the violent crimes they investigate. To pick on the Murder Investigation Manual, although it briefly mentions how cognitive bias can affect a murder investigation, it does not extend to giving advice on identifying and dealing with the potential cognitive and emotional stressors associated with investigating such crimes. This is surprising perhaps when such stressors have been shown to be common contributors to erroneous decision-making and consequently investigative failure (Rossmo 2009).

\section{Investigating Suspicious Child Death}

Children are not meant to die and the police investigation into the sudden death of a child must be influenced by this basic fact (Investigating Suspicious Child Death, Association of Chief Police Officers, 2014, p.4).

This quote taken directly from the guidance available to police investigators of suspicious child death (including murder) hints that there is a discernible difference between how officers will experience (and be affected by) child homicide investigations when compared with adult homicides. This is not surprising if one considers the unlawful killing of another human being (by means of murder and manslaughter) to be the most serious of crimes; then when the victim is a child, most of us will view it to be all the more heinous (Adler and Polk 2008; Roach and Bryant 2015). Additionally, the investigation of the death of a child often carries an even greater weight of investigative sensitivity due to the family's and public's disgust and outrage and high expectation that justice will and must be served. Thankfully, there is some cause for optimism. John Fox (a former UK homicide detective) states that the police response to suspicious child death has come a long way since the 1990 s, when

..even if experienced detectives attended (a SUDI. ${ }^{1}$ ), their basic training in crime scene investigation would sometimes cause them to over-react, thereby causing great distress to bereaved parents, most of whom were innocent of any wrong doing (2007, p.132).

In the UK, the tragic death of school-girl Victoria Climbie, tortured and killed by her guardians in 2000 , acted as a catalyst

\footnotetext{
${ }^{1}$ The Sudden and Unexplained Death of an Infant (SUDI) is not widely referred to in this paper as it tends to be used to describe victims who are young children (often babies) and not older children of 16 or 17 years. As this paper is concerned with the effects of all suspicious child deaths, it was not considered inclusive enough to be generically used here.
}

for change, leading first to a public enquiry and to the numerous changes in child protection policies in the UK, including how police investigators should conduct investigations into suspicious child deaths. When, however, we recently reviewed numerous multi-agency protocols and their various iterations (e.g. Working Together to Safeguard Children 2006; $2010 ; 2013 ; 2015^{2}$ ), the specific guidance developed for police investigators (e.g. A Guide to Investigating Child Deaths, ACPO 2014) and the content of courses developed for criminal investigators and other related professionals (e.g. Investigating Child Death) which amounted to thousands of pages in total, we found no mention of how investigators might deal or cope with such emotional, stressful and distressing cases. Quite rightly, much time and space is dedicated to how those close to the victim should be treated in the investigation of a child death (e.g. A Guide to Investigating Child Death 2014) and handbooks (e.g. Marshall 2012; Sidebotham and Fleming 2007). Similarly, we found research which focused on what bereaved parents want from professionals (including police) after the sudden death of their child (e.g. Garstang et al. 2014 ${ }^{3}$; Garstang et al. 2015). But to restate the point, we did not find anything that mentioned the cognitive and emotional stressors likely to be experienced by police investigators of child homicide (and suspicious child death). In sum, little or nothing is presented about how they might deal with or cope in such investigations.

\section{Police Officer Coping Strategies}

So, how do police officers cope with the stresses and strains of their job and, more importantly, how do homicide investigators?

Obviously, the inherent nature of police work precludes the immediate discharge of emotions. It is certainly not appropriate behaviour for a police officer who has been given the responsibility of maintaining stability in others to ventilate in public (Waters and Ussery 2007, p172)

Our apologies if we have given the impression that police investigators only deal or cope with the stressors and effects of homicide investigations in negative ways, such as an increased intake of alcohol or social isolation. Police officers do of course deal and cope with the stressors and strains of their roles, with some interesting research suggesting a curvelinear relationship between work experience and stress, with those with minimal and extensive job experience least likely to perceive their job or role as stressful (e.g. Violanti 1983; Patterson 1992).

\footnotetext{
2 The 2015 version can be found at https://www.gov. uk/government/publications/working-together-to-safeguard-children-2 (accessed on 15 July 2016).

${ }^{3}$ Provides an excellent meta-analysis of the literature in this area
} 
Academic research in this area both identifies and categorises a number of different 'coping strategies' used by police officers. Waters et al. (1982) for example suggest that these can be categorised according to the source of responsibility, the individual officer or the Department (1982). Of most interest to us here, individual coping strategies include the following:

- The development of a dependable support system (e.g. family, friends and colleagues)

- Improved communication skills (e.g. the ability to discuss their views, opinions and feelings with others)

- A means of ventilating feelings appropriately (e.g. playing sport or having interests outside of work)

- A regular exercise program with minimal time expenditure of $30 \mathrm{~min}$ a session $(1982, \mathrm{p} 25)$

What is not known is (1) how these or others (or these plus others) are used by homicide investigators and how frequently, (2) how they manifest themselves and (3) whether the same stressors and coping strategies are used in child and adult homicide investigations. The answers hold important implications for the welfare and future training of homicide investigators.

\section{The Present Paper}

As the present paper is the first to focus on this area, it is completely exploratory in nature and indeed simply represents the first stage of a wider study of the cognitive and emotional stressors of child homicide investigation on police investigators. The findings are from a survey-based study which examined whether police homicide investigators had experienced different cognitive and emotional stressors (in form and intensity) when investigating child and adult homicide cases and whether they dealt or coped with these in different ways.

\section{Method}

\section{Materials}

The use of any formal psychometric testing (e.g. The Impact of Events Scale-Revised (IEOS-R) by Weiss $2007^{4}$ and The Ways of Coping Questionnaire-Revised WOCQ-R (Lazarus and Folkman 1984$)^{5}$ to identify the cognitive and emotional stressors experienced by investigators and the strategies they use to deal with them was discounted in favour of the

\footnotetext{
${ }^{4}$ Found at http://www.emdrhap.org/content/wp-content/uploads/2014/07 /VIII-E_Impact_of_Events_Scale_Revised.pdf (accessed on 18th July, 2016)

${ }^{5}$ Found at http://www.mindgarden.com/158-ways-of-coping-questionnaire (accessed 18 July 2016)
}

development of a simpler, less formalised and more bespoke survey tool for use with criminal investigators. Moreover, it was feared that if forming psychological testing was employed, it would be likely that respondents would not come forward as they would assume that the study was related to their performance and occupational health. It would, however, be wrong of us not to say that some of the questions contained in the survey were not influenced by the IOES-R and WOCQ$\mathrm{R}$, and this is duly acknowledged.

The present study employed a within-subjects questionnaire design comprising of three sections. ${ }^{6}$ The first section focused on respondents' demographics (e.g. age, police experience, marital status) followed by a second section designed to measure the level of homicide investigative experience, for both adult and child cases. The third section sought to identify the impact of investigating homicide on different forms of cognitive and emotional functioning, with respondents asked to respond to 12 five-point scale questions (ranging from 1 strongly disagree to 5 strongly agree) first on the effects of adult homicide and then as regards child homicide investigations. The presentation of both was randomised to control for order effects. This section focused on what respondents experienced with regard to emotional and cognitive stressors such as pressure to solve a case, sleeping patterns, their perception of case complexity, intrusive thoughts regarding cases, the effect on personal and social life and their ability to think clearly. Questions also explored the different strategies they employed when conducting homicide investigations, for example the importance of the support of colleagues, their reliance on instinct and their reliance on the investigative guidance and manuals available. The fourth and final section of the survey questionnaire asked respondents to answer 13 five-point scale questions that focused specifically on how they dealt with the cognitive and emotional effects and stressors in their mostrecent child homicide investigation. This section orientated the respondent's thoughts, feelings and experiences in relation to their level of focus and concentration, their emotions, any coping strategies employed, job satisfaction and any intrusive thoughts relating to their most recent child homicide case.

\section{Procedure}

Police investigators were invited to take part in the present study through the UK Association of Chief Police Officers' (ACPO as was), Homicide Working Group e-mail register. Respondents were asked to take part if they had experience of investigating both adult and child homicides. Following the initial e-mail to members of the group, the sampling took a snowball approach whereby they were asked to forward the email to colleagues that met the survey criteria. In the e-mail, respondents were provided with a survey information sheet

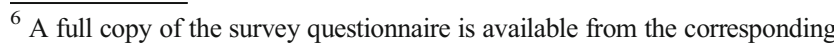
author.
} 
and provided with a URL to the study (hosted using Qualtrics). All respondents were informed that their participation was entirely voluntary, provided with an electronic consent form and asked to work through the questionnaire, which took no longer than $5 \mathrm{~min}$ to complete.

\section{Results}

\section{Survey Questionnaire Part 1—Respondent Demographics}

Ninety-nine police officers with experience of investigating both child and adult homicide cases from 23 different police forces across England and Wales took part in the present study. As can be seen in Table 1, 90.80\% of those included

Table 1 Respondent demographic information

\begin{tabular}{|c|c|}
\hline Demographic variables & Descriptive statistics \\
\hline Age & $\mathrm{M}=46.11, \mathrm{Mdn}=46.00, \mathrm{SD}=6.95$ \\
\hline Ethnicity & $\begin{array}{l}24.20 \%(n=24) \text { White } \\
52.50 \%(n=52) \text { White British } \\
14.10 \%(n=14) \text { White European } \\
5.00 \%(n=5) \text { Other } \\
3.00 \%(n=3) \text { British } \\
1.0 \%(n=1) \text { Black British }\end{array}$ \\
\hline Relationship status & $\begin{array}{l}3.00 \%(n=3) \text { single } \\
5.10 \%(n=5) \text { divorced } \\
12.10 \%(n=12) \text { in a relationship } \\
1.00 \%(n=1) \text { widowed } \\
78.80 \%(n=78) \text { married }\end{array}$ \\
\hline Employment & $\begin{array}{l}99.00 \%(n=98) \text { working within the Police } \\
1.00 \%(n=1) \text { retired }\end{array}$ \\
\hline Education & $\begin{array}{l}27.30 \%(n=27) \text { GCSEs or equivalent } \\
24.30 \%(n=25) \mathrm{A}=\text { levels or equivalent } \\
22.20 \%(n=22) \text { Undergraduate degree } \\
17.20 \%(n-17) \text { Postgraduate qualification } \\
8.1 \%(n=8) \text { Other }\end{array}$ \\
\hline Children & $\begin{array}{l}17.00 \%(n=17) \text { do not have children } \\
83.00 \%(n=82) \text { have at least one child }\end{array}$ \\
\hline Number of children & $\mathrm{M}=2.22, \mathrm{SD}=0.88$ \\
\hline $\begin{array}{l}\text { Age of children } \\
\text { (years) }\end{array}$ & $\mathrm{M}=14.40, \mathrm{SD}=7.67$ \\
\hline Rank in the police & $\begin{array}{l}22.20 \% \%(n=22) \text { Detective Inspector } \\
23.20 \%(n=23) \text { Detective Constable } \\
20.20 \%(n=20) \text { Detective Chief Inspector } \\
8.10 \%(n=8) \text { Detective Superintendent } \\
14.10 \%(n=14.1) \text { Detective Sergeant } \\
2.00 \%(n=21) \text { Detective Chief } \\
\text { Superintendent } \\
10.10 \%(n=10) \text { Other }\end{array}$ \\
\hline Police experience (years) & $\mathrm{M}=21.28, \mathrm{SD}=6.27$, range $=8-43$ \\
\hline
\end{tabular}

in the present study described their ethnicity as White British, White or White European. The majority of respondents were detectives of differing rank ranging from Detective Constable (DC) to Detective Chief Superintendent (DCS) with a further $11.10 \%$ of respondents holding different roles (namely scenes of crime officers). Of the total, $78.8 \%(n=78)$ stated that they were married and $83 \%$ had children.

A variety of descriptive and inferential statistics was employed using IBM SPSS Statistics 19. Parametric statistics were employed within this dataset despite the use of Likert scales due to the fact that research has evidenced that twotailed parametric analyses are in fact robust enough to handle non-normally distributed data (Glass et al. 1972). More specifically, recent research has advocated the use of the $t$ test with Likert scales and the majority of the analyses undertaken in this article are $t$ tests (De Winter and Dodou 2010). Furthermore, Cohen's $d$ (Cohen 1988) was calculated for all applicable analyses to measure effect sizes with a score of 0.2 indicating a small effect, 0.5 a medium effect and 0.8 a large effect.

\section{Survey Questionnaire Part Two-Investigative Experience}

Prior to completing the various five-point scale questions regarding the emotional and cognitive effects of homicide investigation, respondents were asked to state their investigative experience in years. Descriptive statistical analysis found that the average amount of experience respondents had of investigating suspicious death cases was 11.86 years (SD, 6.82, $n=99$ ). The average number of cases respondents had investigated where the victim was an adult was found to be 30.66 cases ( $\mathrm{SD}=31.86, n=58$ ), more than four times the average number of suspicious deaths where the victim was a child $(\mathrm{M}=7.03$ cases, $\mathrm{SD}, 8.83, n=73)$. The average number of unsolved investigations which respondents had worked on where the victim was an adult was found to be 2.37 cases (SD, 4.87, $n=86$ ). Where the victim was a child was again much smaller at 0.51 cases (SD, $1.20, n=88$ ). The ratio of adult to child investigations found in the present study reflects the general patterns for adult and child homicide in England and Wales (Brookman 2005). The average time that had passed since the respondents last investigated an adult homicide was found to be 8.58 months $(\mathrm{SD}=16.46, n=91$ ), whereas for the last child homicide investigation, it was far more distant at 22.79 months $(\mathrm{SD}=41.85, n=94)$.

\section{Survey Questionnaire Part 3-the Cognitive and Emotional Stressors with Investigating Homicide}

Table 2 displays the mean and standard deviations for the respondents' responses to the five-point scale questions investigating the cognitive and emotional stressors, alongside a 
Table 2 Paired sample $t$ tests for the respondents' responses to questions investigating the effect of both adult and child homicide investigations

5-point Likert scale questions

$\begin{array}{lll}\begin{array}{l}\text { Adult } \\ \text { homicide }\end{array} & \begin{array}{l}\text { Child } \\ \text { homicide }\end{array} & \end{array}$

I felt a lot of pressure to get a result as quickly as possible when investigating these cases.

$\begin{array}{llllll}3.37 & 1.31 & 3.14 & 1.41 & 2.15 & .03\end{array}$

0.17

I had trouble sleeping when I was investigating these cases.

I feel that these cases are often the most complex and demanding to investigate.

$\begin{array}{lllllll}2.45 & 1.20 & 2.63 & 1.21 & -1.91 & .06 & -0.15\end{array}$

I became pre-occupied with thoughts relating to these cases even when I was not at work.

$\begin{array}{lllllll}3.04 & 1.02 & 3.69 & 1.15 & -5.45 & .001 & -0.59\end{array}$

I felt that my personal life suffered when investigating these cases.

$\begin{array}{lllllll}3.00 & 1.20 & 3.12 & 1.21 & -1.37 & .18 & -0.09\end{array}$

The support of my colleagues was crucial when I was investigating these cases.

$\begin{array}{lllllll}2.86 & 2.83 & 2.80 & 1.86 & .62 & .54 & 0.03\end{array}$

I tended to rely on my instincts more when investigating these cases.

$\begin{array}{llllllll}3.49 & 1.20 & 3.61 & 1.04 & -1.12 & .27 & -1.00\end{array}$

$\begin{array}{lllllll}2.72 & 0.93 & 2.62 & 1.03 & 1.17 & .25 & 0.09\end{array}$

I felt that colleagues relied on me a lot when investigating these cases.

$\begin{array}{llllllll}3.30 & 1.06 & 3.44 & 1.07 & -1.42 & .16 & -0.13\end{array}$

I often found it difficult to think clearly when investigating these cases.

$\begin{array}{llllllll}1.93 & 0.92 & 2.10 & 0.90 & -1.89 & .06 & -0.72\end{array}$

I felt that the hardest aspect to deal with were the emotional effects generated by investigating these cases. $\begin{array}{lllllllll}2.24 & 0.96 & 2.98 & 1.10 & -7.02 & .001 & -0.72\end{array}$

I tended to find myself thinking about these cases after the investigations had ended $\quad \begin{array}{lllllllllll}2.90 & 1.17 & 3.47 & 1.22 & -4.40 & .001 & -0.48\end{array}$

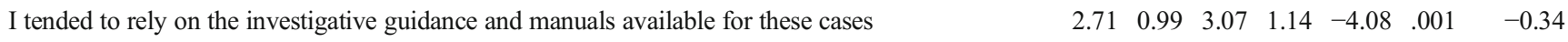

$N=99$

group of optional methods and ways with which respondents might deal with these in adult and child homicide investigations. Paired sample $t$ tests were conducted to examine whether respondents reported differences in the stress effects that investigating adult and child homicide had on them.

As can be seen in Table 2, statistically significant differences were found regarding the pressure felt by respondents when investigating the two different types of homicide, with respondents stating that they feel more pressure to solve an adult homicide quickly than they do a child homicide. A significant difference was also identified relating to the level of complexity experienced in the two types of homicide investigation, with child homicide cases considered to be the more complex and demanding. Respondents also reported that they found the emotional effects of investigating child homicide significantly harder to deal with than that of adult homicides with the level of intrusive thoughts when not at work reported as being higher for child homicide cases. Finally, respondents reported that they tended to use the investigative guidance manuals more when investigating the death of a child than that of an adult, probably best explained by a combination of the perceived complexity and the relative rareness of child homicide by comparison with adult homicide.

Although the findings so far suggest that discernible differences exist in the investigative stressors involved with investigating child and adult homicide, the influence (possibly confounding) of several other important factors need to be first explored before any conclusions can be drawn. The first is the presence of any potential 'recency effect' whereby the most acute investigative effects are felt the more recent the investigation, irrespective of whether it relates to a child or adult homicide. To examine this, respondents were divided into two groups: those that had investigated a homicide within the last 6 months $(n=38)$ and those who had not $(n=56)$. First, an independent samples $t$ test was conducted to identify whether the means (averages) for the scores for the homicide investigation effects questions were different for those who had investigated a child homicide case in the past 6 months than those who had not. In the group that had investigated a child homicide in the last 6 months, respondents reported significantly lower average scores for the effects statements than those in the group that had not investigated a child homicide in the last 6 months $(\mathrm{M}=2.26, \mathrm{SD}=1.01$ and $\mathrm{M}=2.89, \mathrm{SD}=1.29$, respectively $)$ with the $t$ test found to be statistically significant $(t(92)=2.53$, $p=.013$ ) and with the difference of 0.63 indicating a medium effect size $(d=-0.54)$. Additional significant differences between the groups were found specifically in relation to the extent to which they had experienced thoughts relating to the cases when not at work, with those who had investigated a child homicide in the last 6 months $(\mathrm{M}=2.79, \mathrm{SD}=1.17)$ scoring significantly lower than the respondents who had not $(\mathrm{M}=3.41$, $\mathrm{SD}=1.19)(t(92)=2.51, p=.014)$, with the difference of 0.62 suggesting a medium effect size $(d=-0.52)$, and the extent to which they believed their personal life suffered during child homicide investigations with those investigating a case in the past 6 months $(M=2.50, S D=1.20)$ scoring significantly lower than those who had not investigated a case recently $(\mathrm{M}=3.09$, $\mathrm{SD}=1.13)(t(92)=2.42, p=.018)$, with the difference of 0.59 indicating a medium effect $(d=0.51)$. No further significant differences between the groups were found for the remaining questions.

The reader may consider the finding that those who reported that they had experienced the greatest stressors and effects from investigating child homicide, had not been involved with 
a case for more than 6 months, may seem somewhat counterintuitive, and possible explanations for this are offered in the "Discussion" section to follow.

A second possible influential factor on respondent answers was their length of police service. Pearson correlational analyses were conducted to examine whether experience in the Police Service had had an effect on the participants' responses to the questions about the effects of investigating both adult and child homicides. Here, two statistically significant correlations were found for adult homicide investigation: feeling that their colleagues relied on them when investigating adult homicides ( $r=.21, p=.05)$ and in relation to participants' feeling that the support of their colleagues was crucial when I was investigating adult homicides $(r .22, p=.05)$. Pearson correlations were conducted to explore the length of service and responses to the questions regarding their most recent child homicide investigation. A significant positive correlation was found between years in the police service and the amount of job satisfaction that they felt on the successful conclusion of their most recent child homicide case $(\mathrm{r}=.21$, $p=.05$ ). A significant negative correlation was also found between years of service and whether they had thoughts and fantasies about how they wanted their most recent child homicide case to turn out $(\mathrm{r}=.27, p=.01)$.

As a third factor possibly influencing the cognitive and emotional stressors of homicide felt by investigators deemed worthy of exploration concerned their level of investigative experience; the hypothesised direction being the greater the amount of investigative experience, the more likely that any effects and stressors will have to be lessened (or moderated) by that experience (e.g. due to increased de-sensitisation or neutralisation effects). To this end, respondents were asked how many adult and child homicide investigations they had been part of and the results of the correlational analyses are shown in Table 3.

As can be seen, the only significant correlation found for adult homicide investigation was for the question 'the support of my colleagues was crucial when I was investigating these cases', where a weak but significant positive correlation suggests that the more experienced investigator group found the support of their colleagues more crucial. With regard to child homicide investigation, the only significant correlation found was for 'I felt a lot of pressure to get a result as quickly as possible when investigating these cases', where a weak negative correlation was found highlighting that more experienced investigators reported feeling less pressure to get a result as quickly as possible than their more inexperienced colleagues. Overall, the findings suggest that investigative experience in general does not appear to lessen the cognitive and emotional effects experienced by investigators, whether the victim is an adult or a child.

A fourth possibly influential variable was officer rank. For example, did senior officers experience more or less stressors in homicide investigations than those of lower rank and did this hold for both child and adult homicides? To explore this question, respondents were divided into two groups: those of a rank most common for Senior Investigating Officers (e.g. Detective Chief Superintendent, Detective Superintendent and Detective Chief Inspector) $(n=29)$ and those who were $\operatorname{not}(n=59)$. Those who did not indicate that they were detectives were excluded from these analyses $(n=9)$. When applied to the investigating child homicide statements, the SIO group of respondents scored significantly higher than those in the non-SIO group for 'I had trouble sleeping when I was investigating these cases' $(\mathrm{M}=3.07, \mathrm{SD}=1.10$ and $\mathrm{M}=2.34$, $\mathrm{SD}=1.14$, respectively), which was statistically significant

Table 3 Pearson's correlations for homicide investigation experience and respondents' responses to questions investigating the effect of both adult and child homicide investigations

5-point Likert scale questions

Adult homicide

I felt a lot of pressure to get a result as quickly as possible when investigating these cases.

I had trouble sleeping when I was investigating these cases.

I feel that these cases are often the most complex and demanding to investigate.

I became pre-occupied with thoughts relating to these cases even when I was not at work.

I felt that my personal life suffered when investigating these cases.

The support of my colleagues was crucial when I was investigating these cases.

I tended to rely on my instincts more when investigating these cases.

I felt that colleagues relied on me a lot when investigating these cases.

I often found it difficult to think clearly when investigating these cases.

I felt that the hardest aspect to deal with were the emotional effects generated by investigating these cases.

I tended to find myself thinking about these cases after the investigations had ended

I tended to rely on the investigative guidance and manuals available for these cases

\begin{tabular}{|c|c|c|c|}
\hline \multicolumn{2}{|c|}{ Adult homicide } & \multicolumn{2}{|c|}{ Child homicide } \\
\hline$r$ & $p$ value & $r$ & $p$ value \\
\hline-0.06 & 0.55 & $-0.24 *$ & 0.019 \\
\hline 0.04 & 0.72 & 0.01 & 0.96 \\
\hline 0.56 & 0.58 & 0.11 & 0.26 \\
\hline-0.04 & 0.72 & -0.13 & 0.90 \\
\hline 0.12 & 0.24 & -0.003 & 0.98 \\
\hline $0.27^{*}$ & 0.006 & 0.17 & 0.09 \\
\hline 0.10 & 0.32 & -0.10 & 0.35 \\
\hline 0.17 & 0.09 & 0.19 & 0.06 \\
\hline-0.10 & 0.30 & -0.21 & 0.035 \\
\hline 0.01 & 0.93 & -0.040 & 0.68 \\
\hline 0.12 & 0.22 & 0.01 & 0.96 \\
\hline-0.09 & 0.37 & -0.03 & 0.78 \\
\hline
\end{tabular}


$(t(86)=2.86, p=.005, d=0.65)$; 'I feel that these cases are often the most complex and demanding to investigate', $(\mathrm{M}=4.17, \mathrm{SD}=.97)$ than non-SIO group $(\mathrm{M}=3.39$, $\mathrm{SD}=1.18)$, which produced a statistically significant difference $(t(86)=3.11, p=.003, d=.72)$; 'I became pre-occupied with thoughts relating to these cases even when I was not at work' $(\mathrm{M}=3.55, \mathrm{SD}=1.09$ and $\mathrm{M}=2.85$, SD-1.22, respectively) with a $t$ test reporting a statistically significant difference between the two rank groups $(t(86)=2.64, p=.01$, $d=0.61$ ); the extent to which the SIO group felt that their personal life suffered more during child homicide investigations than the non-SIO group $((\mathrm{M}=3.10, \mathrm{SD}=1.01$ and $\mathrm{M}=2.58, \mathrm{SD}=1.2$, respectively) also found to be statistically significant $(t(86)=2.0, p=.048, d=0.47)$; feeling that the support of their colleagues is crucial during child homicide investigations $(\mathrm{M}=3.90, \mathrm{SD}=0.72$ and $\mathrm{M}=3.49, \mathrm{SD}=1.12$, respectively) $(t(79.48)=2.04, p=.044, d=0.44)$ and relying upon the investigative guidance manual in child homicide investigation significantly more $(\mathrm{M}=3.38, \mathrm{SD}=1.12$ and $\mathrm{M}=2.83, \mathrm{SD}=1.15$, respectively $)(t(57.22)=2.56$, $p>.036, d=0.48$ ); and finally, the SIO group scored significantly higher than did non-SIO group $(\mathrm{M}=3.83, \mathrm{SD}=0.89$ and $\mathrm{M}=3.20, \mathrm{SD}=1.16$, respectively) to the extent to which they felt that their colleagues relied upon them in child homicide cases $(t(86)=2.56, p=.012, d=0.61)$. In sum, respondents of SIO rank reported higher cognitive and emotional stressors in investigating child homicide than did their counterparts of lower rank.

Similar 'rank' analysis was conducted with the SIO and non-SIO groups for respondent answers to the questions relating to adult homicide investigation. The results are presented in Table 4. As can be seen, the findings are very similar to those found for child homicide investigation with the SIO group reporting more cognitive and emotional stress than did those of lower rank, but the larger effect sizes found were for child homicide investigations.

A fifth demographic variable to be considered was whether having children would increase the effects (and their intensity) and stress experienced by investigators of child homicide. To explore this, respondents were divided in to two groups: those with children $(n=82)$ and those without $(n=17)$. Independent sample $t$ tests were conducted with the two groups and their answers to the child homicide investigation questions. A statistically significant difference was found between the two groups with those without children scoring lower $(\mathrm{M}=3.94$, $\mathrm{SD}=0.75)$ than those with children $(\mathrm{M}=4.39, \mathrm{SD}=0.68)$ in response to the statements asking about the extent to which they can remain focused during investigations $(t(97)=2.44$, $p=0.017)$, with a difference of 0.45 indicating a medium effect size $(d=-0.63)$, and keeping their emotions to themselves during investigations, with those without children $(\mathrm{M}=2.82, \mathrm{SD}=1.24)$ reported keeping their emotions to themselves significantly less than do those with children $(\mathrm{M}=3.46, \mathrm{SD}=1.20)(t(97)=-1.99, p=0.05)$, with difference of 0.64 suggesting a medium effect size $(d=-0.52)$. No further significant differences in answers were found between those who did and did not have children.

Furthermore, the average age of respondents' children was calculated and Pearson correlational analyses conducted to explore whether the age of a respondent's child/children plays a role in the emotional effects generated when investigating child homicide. The age of the respondents' children was correlated with the questions measuring the effects of child homicide investigation in general. Significant negative

Table 4 Independent samples $t$ test results between SIO ranked officers and non-SIO ranked officers for adult homicide investigation

\begin{tabular}{|c|c|c|c|c|c|c|c|}
\hline \multirow[t]{2}{*}{ 5-point Likert scale questions } & \multicolumn{2}{|c|}{$\begin{array}{l}\text { Non-SIOs } \\
(n=59)\end{array}$} & \multicolumn{2}{|c|}{$\begin{array}{l}\text { SIOs } \\
(n=29)\end{array}$} & \multirow[t]{2}{*}{$\mathrm{t}$} & \multirow[t]{2}{*}{$p$ value } & \multirow[t]{2}{*}{$d$} \\
\hline & M & SD & M & SD & & & \\
\hline I felt a lot of pressure to get a result as quickly as possible when investigating these cases. & 3.19 & 1.28 & 3.59 & 1.32 & -1.36 & .18 & -0.29 \\
\hline I had trouble sleeping when I was investigating these cases. & 2.14 & 1.21 & 2.93 & 1.19 & -3.06 & .003 & 0.42 \\
\hline I feel that these cases are often the most complex and demanding to investigate. & 2.92 & 1.04 & 3.14 & 1.03 & -.95 & .35 & -0.21 \\
\hline I became pre-occupied with thoughts relating to these cases even when I was not at work. & 2.76 & 1.18 & 3.28 & 1.10 & -1.96 & .053 & -0.46 \\
\hline I felt that my personal life suffered when investigating these cases. & 2.54 & 1.24 & 3.21 & 1.05 & -2.49 & .015 & -0.58 \\
\hline The support of my colleagues was crucial when I was investigating these cases. & 3.34 & 1.20 & 3.66 & 0.90 & -1.26 & .21 & -0.30 \\
\hline I tended to rely on my instincts more when investigating these cases. & 2.61 & 0.97 & 2.86 & 0.92 & -1.17 & .25 & -0.26 \\
\hline I felt that colleagues relied on me a lot when investigating these cases. & 3.02 & 1.08 & 3.52 & 0.87 & -2.18 & .032 & -0.51 \\
\hline I often found it difficult to think clearly when investigating these cases. & 1.81 & 0.90 & 2.03 & 0.94 & -1.07 & .29 & -2.4 \\
\hline I felt that the hardest aspect to deal with were the emotional effects generated by investigating these cases. & 2.10 & 1.00 & 2.38 & 0.78 & -1.31 & .19 & -0.31 \\
\hline I tended to find myself thinking about these cases after the investigations had ended & 2.61 & 1.18 & 3.34 & 1.01 & -2.88 & .005 & -0.66 \\
\hline I tended to rely on the investigative guidance and manuals available for these cases & 2.49 & 1.04 & 2.97 & 0.87 & -2.12 & .037 & -0.50 \\
\hline$N=90$ & & & & & & & \\
\hline
\end{tabular}


correlations were found between the age of respondents' children and the following two statements: 'I often found it difficult to think clearly when investigating these cases' $(r=-.22$, $p=.05$ ) and 'I felt that the hardest aspect to deal with was the emotional effects generated by investigating these cases' $(r=-.35, p>.01)$. This suggests that those respondents with younger children reported experiencing a greater level of cognitive and emotional stress when investigating child homicides than adult (albeit a weak correlation was found).

The last variable considered important to understanding the overall findings of this section of the survey questionnaire was whether respondents with undetected homicide cases were more affected by their homicide investigations than are those without unsolved cases. Put another way, would the unsuccessful resolution of a case add to the cognitive and emotional stressors it and others generate? To explore this, respondents were asked to detail how many unsolved adult homicides they had worked on and were then divided into two groups: those without any unsolved homicide cases $(n=35)$ and those with $(n=52)$. Independent samples $t$ tests were then conducted using the answers to the statements about experience of investigating adult homicides and only one significant difference between the two groups' answers was found - those without unsolved cases reported that they rely more on the investigative guidance manuals than those with unsolved cases $(\mathrm{M}=3.11, \mathrm{SD}=0.96$ and $\mathrm{M}=2.44, \mathrm{SD}=0.94$, respectively $)$ $(t(85)=3.24, p=.002, d=0.71)$.

The same analysis was conducted using the answers to the statements relating to the experience of investigating child homicide and again only significant difference found between the two groups with those in with unresolved cases scoring higher on the statement 'I tend to find these cases the most complex and demanding to investigate' $(n=22)(\mathrm{M}=4.14, \mathrm{SD}=0.99$ and $n=66$,
$\mathrm{M}=3.5, \mathrm{SD}=1.19$, respectively $)(t(86)=2.36$, $p=.02, d=0.58$ ).

\section{Survey Questionnaire Part 4-Dealing and Coping with the Effects of the Most Recent Child Homicide Investigation}

The fourth and final section of the survey questionnaire asked respondents how they had dealt (or coped) with the effects of their most recent child homicide investigation (some were currently working on them). To explore further our previous finding that respondents reported that with child homicide, the more recent the investigation the less the cognitive and emotional effects experienced, respondents were again divided into two groups: those who had investigated a child homicide in the last 6 months and those who had not. Independent samples $t$ tests were conducted on answers to the statements about dealing and coping with the cognitive and emotional effects generated by child homicide investigations. The results are displayed in Table 5.

As can be seen, there were some differences between the two groups with those that had not investigated a child homicide in the last 6 months scoring higher than those who had not, for the statement, remaining focused on what they had to do next $(t(92)=2.46, p=.016, d=0.51)$. A further finding of significance was that the 'not in the past 6 months group' agreed more with the statement that they could have coped better to a greater extent $(\mathrm{M}=2.07, \mathrm{SD}=0.95$ and $\mathrm{M}=1.66$, $\mathrm{SD}=0.91$, respectively) than did those who had not $(t$ $(92)=2.11, p=.038, d=0.44)$. A final difference found was that the not in the past 6 months group also agreed more with the statement $I$ avoided people more than normal during the investigation than did the within the last 6 months group $(t$ $(92)=1.98, p=.05, d=0.43)$. No further significant
Table 5 Respondents' level of coping during most recent child homicide investigation

\begin{tabular}{lcc}
\hline During my most recent child homicide investigation: & M & SD \\
\hline I remained focused on what I had to do next. & 4.31 & 0.71 \\
I hoped that the investigation would solve itself. & 1.94 & 1.17 \\
I found someone who was a good listener. & 2.67 & 0.92 \\
I kept my emotions to myself. & 3.35 & 1.22 \\
I found ways to let off steam. & 3.08 & 1.02 \\
I avoided people more than normal. & 1.79 & 0.85 \\
I didn't let the situation get to me and I refused to think about it too much. & 2.97 & 1.03 \\
I saw it as my problem and doubled my efforts to solve it. & 2.79 & 1.21 \\
I focused more on things that I enjoyed outside of work. & 2.58 & 0.94 \\
I had thoughts and fantasies about how I wanted it to turn out. & 2.19 & 1.32 \\
I felt that I could have coped better and let the investigation get to me. & 1.91 & 0.95 \\
I felt that the support of family and friends helped me deal with the investigation. & 2.94 & 1.17 \\
I felt a large amount of job satisfaction from the successful conclusion of the homicide investigation. & 4.05 & 1.08 \\
$N=99$ & \\
\hline
\end{tabular}


differences were found between the two groups, suggesting that whether respondents' most recent child homicide investigation was in the last 6 months or longer did not appear to influence how they dealt with the effects of investigating a child homicide.

Having earlier identified that respondents of SIO rank reported feeling the stress effects of investigating child homicide greater than did their less senior counterparts, it was considered important to explore whether they dealt differently with these. Independent sample $t$ tests were conducted using the $\mathrm{SIO}$ and non-SIO grouping and their responses to the statements in the "Results" section (listing coping strategies that might have been adopted in their most recent child homicide investigation). A difference was found in their response to ' $I$ saw it as my problem and doubled my efforts to solve it', where those in the SIO group indicated that it had more effect on them than the non-SIO group $\operatorname{did}(\mathrm{M}=3.17, \mathrm{SD}=1.04$ and $\mathrm{M}=2.42, \mathrm{SD}=1.15$, respectively $)(t(86)=2.97, p=.004$, $d=0.68$ ).

Lastly, the question whether of levels of investigative experience had any influence on respondents' coping strategies when investigating child homicides was explored. Pearson's correlational analysis was conducted with the number of child homicides each respondent had investigated and the questions listed in Table 5. A significant weak positive correlation $r=.24$ was found between the number of child homicides investigated and respondents' responses to the statement ' $I$ hoped that the investigation would solve itself' $(p=.05)$, with a further significant weak negative correlation found $(r=-.28)$ for 'I found someone who was a good listener' $(p=.05)$. More experienced officers reported being less likely to seek out somebody to talk with during an investigation than did their less experienced counterparts. This is further supported by finding a positive weak correlation $(r=.270$ found for child homicide investigation experience and 'I kept my emotions to myself' $(p=.05))$. No further significant correlations were found for this section on strategies to deal with the effects of child homicide investigation, according to levels of investigative experience.

\section{Discussion}

The present study, although admittedly only exploratory in nature, does provide evidence to support the idea that police investigators experience different cognitive and emotional stressors and effects when investigating child homicide compared with that of an adult homicide. The findings have implications for better understanding how police homicide investigators make decisions and for the practical implications concerning the cognitive and emotional well-being of investigators.

\section{Investigative Decision-Making in Child Homicide}

As stated, much of the extant research on investigative decision-making relates to cognitive bias in homicide investigations but does not discriminate between child and adult homicides (e.g. Rossmo 2009; Ask and Granhag 2007; Stelfox and Pease 2005). The principal finding of this study that discernible differences exist between the cognitive and emotional stressors experienced in child homicide investigations and those in adult homicides suggests that this needs to be acknowledged when looking at how and when investigators make key decisions (e.g. Fahsing and Ask 2013; Wright 2013). Further research is needed to explore whether any common psychological frame used by investigators in adult homicides is the same as that used in child homicide investigations and if not, how this might affect subsequent decision-making process?

The findings of the present research highlight several common ways by which investigators deal with the cognitive and emotional stressors and effects from investigating child homicide (e.g. support of colleagues), but the surface is merely scratched here. Further research is needed to illuminate specifically how investigators cope with the effects of such heartbreaking investigations both 'positively' (e.g. sport and physical exercise and sharing thoughts with loved ones) and 'negatively' (e.g. having trouble sleeping or drinking more than usual). Again, areas we are exploring in one-to-one interviews in a sister paper.

One possible outcome of this research might be the development of a bespoke self-report questionnaire for homicide investigators to complete both during and after an investigation (e.g. 6 months later) to help them to self-assess the effects of an investigation is having and has had on them. It is common, however, for investigators to be involved continuously with homicide investigations without a sufficient break in time with which to reflect. Further research is needed to explore how investigators deal any possible cumulative effects.

\section{Practical Implications for Police Homicide Investigators}

The findings of this study have several important practical implications for understanding how the cognitive and emotional stressors in child homicide investigation affect investigators in different ways and different levels of intensity compared to adult homicide investigations. These are summarised briefly below.

First, those who have not been involved in a child homicide investigation for more than 6 months reported the cognitive and emotional effects to be greater than those who had conducted more recent investigations. This is important as it suggests that a significant period of reflection is needed after the investigation has ended in order for investigators to realise the true extent of how their 
investigations have affected them. It is likely that during a child homicide investigation, the need to resolve a case satisfactorily and as quickly as possible will perhaps mask (or delay) the true effect that such cases have on police investigators. Interestingly, this was not found to be the case with adult homicides, suggesting an important area of training for investigators of child homicide whereby they are made aware of the common investigative effects (including cognitive and emotional bias) associated with this type of investigation and when they are most likely to occur. In addition, this finding emphasises the necessity for investigators to be offered the opportunity for full discussion of the investigation 6 months after completion; by offering targeted support and discussions of how the investigator has been since the investigation ended will allow forces to deploy effective and meaningful support. Indeed, this is an avenue that we intend to explore by conducting semi-structured interviews with police homicide investigators, to identify how individual forces can better support those who have to deal with child homicide in the future.

Second, the present study has provided evidence that investigative experience does not seem to protect investigators against the effects of homicide investigation, whether the victim is an adult or a child, suggesting that de-sensitisation does not kick in for many. Indeed, we found little evidence that the length of police service provides little by way of protection against the stressors of child homicide investigation, as was found to be the case in studies of stress in more mainstream policing roles (Violanti 1983; Patterson 1992). We intend to explore this more in future interviews with police homicide investigators as the results of the present study suggest that those who have more child homicide experience tend to hope the investigation will solve itself and tend to internalise their emotions not seeking support from others; this presents implications for those who may be the dedicated well-experienced child homicide investigator.

Third, respondents reported that they tended to use the investigative guidance manuals more when investigating the death of a child than that of an adult. This is probably best explained by a combination of the perceived complexity and the relative rareness of child homicide in comparison with adult homicide. This does offer some justification for the existing ACPO guide specifically for investigating suspicious child deaths, but that there is a need for further and additional guidance for police investigators in this area which includes what the likely cognitive and emotional investigative effects and common stressors are and how investigators might recognise and deal with them.

Fourth, as those investigators with children (particularly young ones) reported being most affected by child homicide investigation, it suggests as much as they might try, work-life separation is difficult in these circumstances, making them particularly vulnerable to the emotional effects of such investigations. This is an important practical implication that has the potential to adjust the ways in which investigators are deployed.

The present study like all research has limitations that must be acknowledged. Firstly, 99 respondents may seem too small a sample size, but the truth is that it is impossible to say how many detectives in England and Wales have experience of investigating both adult and child homicide. The Council of Chief Officers, Suspicious Child Death Investigation Group, e-mailed a link to our survey questionnaire to their members on our behalf. Police investigators from 30 of the 43 (70\%) Police Forces in England and Wales responded to the survey, adding support to the claim that the findings were representative to a satisfactory degree. Second, it was decided that the present study would not look for differences according to gender and so respondent gender was not asked for, which with hindsight might have been a mistake, whether, for example, female investigators deal or cope differently with the investigative effects than do their male counterparts. Judging, however, from the names in the e-mail addresses left by those prepared to take part in a second stage of the study, no more than $10 \%$ of respondents were female. We intend to target a number of female investigators for interviewing in stage two.

In sum, the present study suggests that police homicide investigators do experience different cognitive and emotional effects (in both type and intensity) when investigating child as opposed to adult homicides. It is acknowledged that this is merely a starting point. Further research is needed which explores how investigators identify and deal with these effects (both commonly and individually), which can be expanded to other professionals involved with the suspicious death of a child, such as paediatricians, child protection professionals, pathologists and Scenes of Crimes Officers (SOCO's). Further research must continue to explore how investigative decisions are made in such difficult and stressful circumstances if we are to give those good enough to do it as much self-protection as possible.

Acknowledgments The writers would like to thank all those who responded to the survey and give special thanks to Detective Chief Inspector Ceri Hughes, from South Wales Police, for making this study possible. 
Open Access This article is distributed under the terms of the Creative Commons Attribution 4.0 International License (http:// creativecommons.org/licenses/by/4.0/), which permits unrestricted use, distribution, and reproduction in any medium, provided you give appropriate credit to the original author(s) and the source, provide a link to the Creative Commons license, and indicate if changes were made.

\section{References}

Abdollahi MK (2002) Understanding police stress research. Journal of Forensic Psychology Practice 2(2):1-24

Adler C, Polk K (2008) Child victims of homicide. Cambridge University Press, Cambridge

Anshel M (2000) A conceptual model and implications for coping with stressful events in police work. Criminal Justice Behavior 27:375-400

Ask K, Granhag P (2007) Motivational bias in criminal investigators' judgments of witness reliability. J Appl Soc Psychol 37(3):561-591

Association of Chief Police Officers (2005a) Practice advice on core investigative doctrine. Bramshill: National Centre for Policing Excellence

Association of Chief Police Officers (2005b) Guidance on major incident room standardised administrative procedures (MIRSAP). Wyboston: National Centre for Policing Excellence

Association of Chief Police Officers of England and Wales (ACPO) (2006) Murder investigation manual. Bramshill: National Centre for Policing Excellence

Association of Chief Police Officers of England and Wales (ACPO) (2014) A guide to investigating child deaths. Bramshill: National Centre for Policing Excellence

Bittner E (1990, (1970) The functions of the police in modern society. Oelgesschlager, Gunn and Hain, Cambridge

Brookman F (2005) Understanding homicide. Sage, London

Cohen J (1988) Statistical power analysis for the behavioral sciences, 2nd edn. Erlbaum, Hillsdale

De Winter J, Dodou D (2010) Five-point Likert items: t test versus MannWhitney-Wilcoxon. Practical Assessment, Research \& Evaluation 15(11)

Fahsing I, Ask K (2013) Decision making and decisional tipping points in homicide investigations: an interview study of British and Norwegian detectives. J Investig Psychol Offender Profiling 10: $155-165$

Finn P, Tomz JE (1996) Developing a law enforcement stress program for officers and their spouses. National Institute of Justice, Washington. $\mathrm{DC}$

Fox J (2007) Police investigation in unexpected childhood deaths. In: Sidebotham P, Fleming P (eds) Unexpected death in childhood, A Handbook for Practitioners. Wiley, Chicester, pp. 132-153

Garstang J, Griffiths F, Sidebotham P (2014) What do bereaved parents want from professionals after the sudden death of their child? A systematic review of the literature. BMC Pediatr 14:269

Garstang J, Ellis C, Sidebotham P (2015) An evidence-based guide to the investigation of sudden unexpected death in infancy. Forensic Science and Medical Pathology 11:345-357

Glass GV, Peckham PD, Sanders JR (1972) Consequences of failure to meet the assumptions underlying the fixed effects analysis of variance and covariance. Rev Educ Res 42:237-288

Hart PM, Wearing AJ, Headey B (1993) Police stress and well-being: integrating personality, coping and daily work experiences. J Occup Psychol 68(2):133-157
HM Government (2006: 2010; 2013; 2015) Working together to safeguard children. Department for Education and Skills. London

Holmberg U, Christianson SA, Karlsson I (2004) Stressful event exposure is related to police officers' attitudes to interviewing crime victims and suspects. A Paper in Ulf Holmberg PhD. Thesis, Department of Psychology, Stockholm University, Stockholm

Huey L, Broll R (2015) I don't find it sexy at all': criminal investigators' views of media glamorization of police 'dirty work'. Policing and Society: An International Journal of Research and Policy 25(2):236247. doi:10.1080/10439463.2013.864654

Kohan A, O'Connor BP (2002) Police officer job satisfaction in relation to mood, well-being, and alcohol consumption. J Psychol 136(3): 307-319

Lazarus RS (1966) Psychological stress and the coping process. McGraw-Hill, New York

Lazarus RS, Folkman S (1984) Stress, appraisal, and coping. Springer, New York

Marshall D (2012) Effective investigation of child homicide and suspicious deaths. Oxford University Press, Oxford

Nicol C, Innes M, Gee D, Feist A (2004) Reviewing murder investigations: an analysis of progress reviews from six police forces. Home Office Online Report, 25/04

Oliver WM, Meir CA (2004) Stress in small town and rural law enforcement: testing the assumptions. Am J Crim Justice 29(1):36-56

Patterson BL (1992) Job experience and perceived job stress among police, correctional, and probation/parole officers. Criminal Justice Behaviour 19(3):260-285

Roach J, Bryant R (2015) Child homicide: generating victim and suspect risk profiles. Journal of Criminal Psychology 5(3):201-215

Roach J, and Pease K (2009) Necropsy and the cold case. In: Rossmo DK (ed) Criminal investigative failure. CRC Press, Boca Raton

Rossmo DK (ed) (2009) Criminal investigative failures. CRC Press, Boca Raton

Salo I, Allwood CM (2011) Decision-making styles, stress and gender among investigators. Policing: An International Journal of Police Strategies and Management 34(1):97-119

Sidebotham P, Fleming P (eds) (2007) Unexpected death in childhood. A handbook for practitioners. Wiley, Chicester

Smith N, Flanagan C (2000) The effective detective: identifying the skills of an effective SIO. Police Research Series, 122. London: UK Home Office

Stelfox P, Pease K (2005) Cognition and detection: reluctant bedfellows? In: Smith M, Tilley N (eds) Crime science: new approaches to preventing and detecting crime. Willan Publishing, Cullompton

Violanti JM (1983) Stress patterns in police work: a longitudinal study. Journal of Police Science Administration 11:211-216

Violanti JM (2005) Dying for the job: psychological stress, disease and mortality in police work. In: Copes K (ed) Policing and stress. Prentice Hall, Upper Saddle River

Waters J, Ussery W (2007) Police stress: history, contributing factors, symptoms, and interventions. Policing: An International Journal of Police Strategies and Management 30(2):169-188

Waters J, Irons N, Finkle E (1982) The police stress inventory: a comparison of events affecting officers and supervisors in rural and urban areas. Police Stress 5(1):18-25

Weiss DS (2007) The impact of event scale-revised. In: Wilson JP, Keane TM (eds) Assessing psychological trauma and PTSD: a Practitioner's handbook, 2nd edn. Guilford Press, New York, pp. 168-189

Wright M (2013) Homicide detectives' intuition. J Investig Psychol Offender Profiling 10:182-199 